\title{
Erratum to: Left-right asymmetry and morphological consequences of a host shift in the oligophagous Neotropical moth Macaria mirthae (Lepidoptera: Geometridae)
}

\author{
Hugo A. Benítez ${ }^{1,2} \cdot{\text { Héctor A. } \operatorname{Vargas}^{3} \text { - Thomas A. Püschel }}^{1}$
}

Published online: 10 June 2015

(C) Springer International Publishing Switzerland 2015

\section{Erratum to: J Insect Conserv \\ DOI 10.1007/s10841-015-9779-0}

The original version of the article has been published with certain errors that are corrected in this erratum.

In Table 1, ME should be removed because it has an error in its ME magnitude. The correct ME values are presented in Tables 2 and 3. Therefore, Table 1 should not be considered.

Therefore, the first sentence of the result section should read "The Procrustes ANOVA applied to assess the measurement error showed that MS individual variation due to FA exceeded the measurement error (Tables 2, 3)."

The online version of the original article can be found under doi:10.1007/s10841-015-9779-0.

Hugo A. Benítez

hugo.benitez@postgrad.manchester.ac.uk

1 Faculty of Life Sciences, University of Manchester, Michael Smith Building, Oxford Road, Manchester M13 9PT, UK

2 Instituto de Alta Investigación, Universidad de Tarapacá, Casilla 7-D, Arica, Chile

3 Departamento de Recursos Ambientales, Facultad de Ciencias Agronómicas, Universidad de Tarapacá, Arica, Chile 